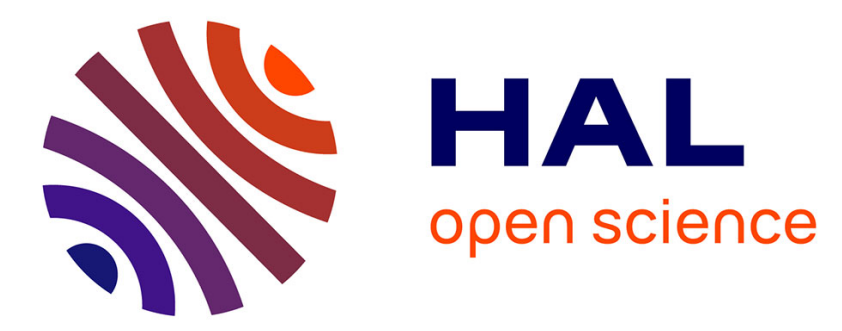

\title{
Hydrodynamics of gas-liquid dispersion in transparent Sulzer static mixers SMX TM
}

\author{
Marco Scala, Lionel Gamet, Louis-Marie Malbec, Huai-Zhi Li
}

\section{To cite this version:}

Marco Scala, Lionel Gamet, Louis-Marie Malbec, Huai-Zhi Li. Hydrodynamics of gas-liquid dispersion in transparent Sulzer static mixers SMX TM. Chemical Engineering Science, 2020, 213, pp.115398. 10.1016/j.ces.2019.115398 . hal-02447553

\section{HAL Id: hal-02447553 \\ https://hal-ifp.archives-ouvertes.fr/hal-02447553}

Submitted on 21 Jan 2020

HAL is a multi-disciplinary open access archive for the deposit and dissemination of scientific research documents, whether they are published or not. The documents may come from teaching and research institutions in France or abroad, or from public or private research centers.
L'archive ouverte pluridisciplinaire HAL, est destinée au dépôt et à la diffusion de documents scientifiques de niveau recherche, publiés ou non, émanant des établissements d'enseignement et de recherche français ou étrangers, des laboratoires publics ou privés. 


\section{Hydrodynamics of gas-liquid dispersion in transparent Sulzer static mixers SMX $\mathbf{S M}^{\mathrm{TM}}$}

\section{$\underline{\text { Marco Scala }}{ }^{1}$, Lionel Gamet ${ }^{2}$, Louis-Marie Malbec ${ }^{3}$, Huai-Zhi Li $^{4}$}

1 IFPEN Rond-point de l'échangeur de Solaize BP 3, 69360 Solaize, France, Marco.scala@ifpen.fr (corresponding author)

2 IFPEN Rond-point de l'échangeur de Solaize BP 3, 69360 Solaize, France, Lionel.gamet@ifp.fr

${ }^{3}$ IFPEN 1 et 4, avenue de Bois-Préau, 92852 Rueil-Malmaison Cedex, France, Louismarie.malbec@ifp.fr

${ }^{4}$ LRGP CNRS 1, rue Grandville, BP 20451, 54001 Nancy Cedex, France Huai-Zhi.Li@univlorraine.fr

\section{Abstract}

The gas-liquid hydrodynamics in a Sulzer $\mathrm{SMX}^{\mathrm{TM}}$ static mixer was investigated in the present work through two different optical techniques: Backlight Shadowgraph Technique (BST) and Particle Image Velocimetry (PIV). 3D printed static mixers were manufactured using transparent plastic in order to provide optical access. The normal-heptane was used as the continuous liquid phase. Three different lengths of mixers and different gaseous nitrogen flow rates were investigated. The flow pattern in an empty tube without the mixing device was used as a reference. Bubble diameter distributions at the inlet and outlet of the SMX mixer were evaluated. The velocity fields inside the mixers were quantified. The gas holdup was also examined. These original results allow to appreciate the SMX static mixer's 
performance and thus to open new industrial applications involving gas-liquid flows such as striping and purification of liquids by a gas.

\section{List of symbols}

\begin{tabular}{|c|c|c|}
\hline Symbol & Units & Description \\
\hline$d_{32}$ & $\mathrm{~m}$ & Sauter diameter \\
\hline$d_{b}$ & $\mathrm{~m}$ & Bubble diameter \\
\hline$d_{c}$ & $\mathrm{~m}$ & Column diameter \\
\hline$d_{e}$ & $\mathrm{~m}$ & Equivalent bubble diameter \\
\hline$d_{n}$ & $\mathrm{~m}$ & Nozzle diameter \\
\hline$E$ & - & Aspect ratio \\
\hline$h$ & $\mathrm{~m}$ & Liquid level \\
\hline$Q_{G}$ & $\mathrm{~m}^{3} / \mathrm{h}$ or $\mathrm{L} / \mathrm{h}$ & Gas phase volumetric flow rate \\
\hline$R e$ & - & Reynolds number \\
\hline$\vec{V}$ & $\mathrm{~m} / \mathrm{s}$ & Mean velocity vectors \\
\hline$V_{T}$ & $\mathrm{~m} / \mathrm{s}$ & Bubble terminal velocity \\
\hline$V_{s}$ & $\mathrm{~m} / \mathrm{s}$ or $\mathrm{mm} / \mathrm{s}$ & Superficial gas velocity \\
\hline$\varepsilon_{G}$ & - & Gas hold-up \\
\hline$\rho_{L}$ & $\mathrm{~kg} / \mathrm{m}^{3}$ & Liquid density \\
\hline$\sigma$ & $\mathrm{N} / \mathrm{m}$ & Surface tension \\
\hline
\end{tabular}

\section{List of abbreviations}




\begin{tabular}{cc}
\hline 2D & Two dimensional \\
\hline 3D & Three dimensional \\
\hline BST & Back Light Shadowgraph \\
\hline CAD & Computer-Aided Design \\
\hline PIV & Particle Image Velocimetry \\
\hline SMX & Kind of Sulzer static mixer \\
\hline
\end{tabular}

\section{Keywords}

Hydrodynamics, Sulzer static mixer SMX ${ }^{\mathrm{TM}}$, Multiphase flow, G-L dispersions, Process intensification, Particle image velocimetry (PIV).

\section{Introduction}

In chemical industrial processes, the mixing and blending of fluids is a common and widely used operation. One of the main objectives of this process is to increase the interfacial area between the phases to improve mass and heat transfer in order to facilitate heterogeneous chemical reactions. Stirred tanks and bubbles columns are largely utilized as reactors to achieve the mixing and blending tasks (Sánchez Pérez et al. 2006). Certain developments and studies in mixing have revealed that similar results can be achieved by using alternative devices such as static mixers (Thakur et al. 2003). The static mixers consist of a series of elements. Each of them is designed to split and recombine the flow (Heyouni et al. 2002). Over the last two decades, the research on static mixers gained renewed interest due to an increasing demand for efficient mixing devices in the industry. Compared to stirred tanks, the 
static mixers do not have any mobile part and present good mixing performance for a reduced energy consumption (Thakur et al. 2003). Furthermore, they present low maintenance cost and easy installation (Madhuranthakam et al. 2009b).

In recent decades, the growing number of studies led to the birth of more and more geometries to cover a wide range of industrial applications. Several designs of static mixers are available nowadays. A classification based on the internal structure of the basic element allows us to assemble them into five mains categories: open design with helical elements, open design containing blades, multilayers design, corrugated plates design and closed design in which the elements have helical or blade shapes (Thakur et al. 2003).

Much of the current literature on static mixers pays attention to the examination of mixing capacity of liquid/liquid dispersions and related applications. For instance, several authors have estimated the mixing performances for several mixer geometries by injecting polymers, by injecting dye fluids, by performing CFD simulations, or by using Laser Induced Fluorescence technique in the static mixers (Pahl and Muschelknautz 1982; Rauline et al. 1998; Lemenand et al. 2003; Meijer et al. 2012; Das et al. 2013; Ghanem et al. 2014; Montante et al. 2016). Other authors investigated the static mixers using the PIV mainly in single phase or liquid-liquid flows in recent years (Voulgaropoulos and Angeli 2017; Alekseev et al. 2017). To the best of our knowledge, the high frequency PIV has never been employed in gas-liquid flows in previous works.

A considerable number of studies have sought to determine the most suitable device conformation for each industrial application (Hobbs and Muzzio 1998; Byrde and Sawley 1999; Rauline et al. 2000; Ugwu et al. 2002; Regner et al. 2006; Meijer et al. 2012; Paglianti and Montante 2013; Park et al. 2014). In gas/liquid dispersions, an open geometry with blades is usually recommended and employed (Thakur et al. 2003; Madhuranthakam et al. 2009a). In recent decades, there has been an increasing amount of literature and studies on gas/liquid 
dispersions using static mixers (Chisti et al. 1990; Paul et al. 2004; Al Taweel et al. 2005; Fradette et al. 2006; Keshav et al. 2008; Madhuranthakam et al. 2009a; Tizaoui and Zhang 2010). In view of all that has been mentioned so far, one may suppose that the $\mathrm{SMX}^{\mathrm{TM}}$ Sulzer static mixer is highly adapted for this dispersion, since this mixing device is structured with oblique open blades. The present study examines the interaction between two different phases of a gas-liquid dispersion and the SMX in a laminar flow regime. Local turbulent perturbations cannot be excluded.

As a starting point of the investigation, the organic liquid is kept stationary and its motion is induced by gas bubbles rising through it. Among classical gas-liquid contactors, the liquid phase is usually stagnant in bubble columns while it can be either stagnant or mobile in structured packings (Engel et al. 2001; Wild et al. 2003; Luo et al. 2008). The static mixers are quite similar to packings. Even if the liquid motion was effectively considered in this work, the negligible effect compared to a stagnant liquid allowed to focus on the case of a stagnant liquid. The major objective of this work is to apply sophisticated methods to analyze the behavior of the SMX ${ }^{\mathrm{TM}}$ Sulzer static mixer in these conditions. Furthermore, the stagnant liquid allowed either to perform the analysis with fewer errors or to serve as a reference for further investigation with a flowing liquid.

The initial objective of this study is to address the feasibility of using static mixers for G/L applications in chemical engineering, like for liquid stripping or for treatment of gases. The results gained in this study will be further harnessed to develop a model of G/L interfacial exchange in the $\mathrm{SMX}^{\mathrm{TM}}$ Sulzer static mixer as well as a bubble breakup and coalescence model. The present paper characterizes the hydrodynamics of the SMX by using two optical methods: the Particle Image Velocimetry (PIV) and the Backlight Shadowgraph Technique (BST). The above techniques were commonly employed to investigate the hydrodynamics of multiphase flows (Chen and Fan 1992; Delnoij et al. 1999; Delnoij et al. 2000; Deen et al. 
2002a; Deen et al. 2002b; Boyer et al. 2002; Zaruba et al. 2005; Deen et al. 2010; Willems et al. 2010; Sathe et al. 2010; Sobieszuk et al. 2012; Sathe et al. 2013; Ayati et al. 2015; Laupsien et al. 2017). Most of the previous studies used these optical techniques for studying bubble columns, microreactors and gas-liquid-solid fluidized beds. For instance, Deen et al. (2010) introduced innovative PIV pre-processing technique for single and two phases flows. Willems et al. (2010) used PIV in liquid and gas/liquid flows through spacer filled channels. In the present study, we applied similar techniques to quantify the flow pattern inside the SMX static mixer. The main objective of this work is to present an innovative experimental investigation of gas-liquid flows in the static mixers. Furthermore, the main advantages and drawbacks of the Backlight Shadowgraph Technique (BST) and Particle Image Velocimetry (PIV) were reported. The gas hold-up in different operating conditions is also estimated. This is an important parameter as it is related to the interfacial area between the phases. The effect of the SMX mixing elements on the velocity flow field is quantified.

As mentioned above, experiments with liquid circulation, both counter-current and cocurrent, were nevertheless carried out to verify the congruence of results. The findings highlighted no relevant difference when the liquid flows in the laminar regime, namely $\operatorname{Re}<$ 15 ( $\mathrm{Li}$ et al. 1997). The bubbles distributions, mean bubble diameters and velocities remained almost unchanged. The highest deviations observed of these last two parameters were lower than $2 \%$.With respect to bubbly flows in a bubble column without internals, a static mixer in a column opens new applications for gas-liquid flows and also presents more challenging issues as packing optical obstruction for the PIV technique. To our best knowledge, there is no work reported yet in the literature within a transparent static mixer thanks to the recent technique of $3 \mathrm{D}$ printing. 


\section{Experimental setup}

\subsection{Fluids used in the experiments}

For the present research, the normal-heptane was chosen as continuous phase. This liquid compound represents an optimal compromise between similar physical properties to some industrial feed (gasoline, for instance) and safety issues in the laboratories. Furthermore, the n-heptane's chemical inertness ensures the reproducibility of the experiments. For the gas phase, nitrogen was selected to be the dispersed phase because it is a non-reactive and stable compound. Taken together, both fluids guaranteed a high number of re-uses of the same solution. The n-heptane has a density of $684 \mathrm{~kg} / \mathrm{m}^{3}$ and a viscosity of $4.10 \times 10^{-4} \mathrm{~Pa} \mathrm{~s}$. The surface tension between the nitrogen and the n-heptane is $0.020 \mathrm{~N} / \mathrm{m}$. Three different flow rates were examined: $1 \mathrm{~L} / \mathrm{h}, 2.5 \mathrm{~L} / \mathrm{h}$ and $5 \mathrm{~L} / \mathrm{h}$. The corresponding superficial velocities were $1.35 \mathrm{~mm} / \mathrm{s}, 3.37 \mathrm{~mm} / \mathrm{s}$ and $6.74 \mathrm{~mm} / \mathrm{s}$.

\subsection{Set-up}

The investigation methodologies, namely PIV and shadowgraph technique, require a clear optical access to the system. This conducted us to use transparent materials. The cylindrical column, made of glass, was placed inside a box of squared section in order to reduce image distortion. This external jacket was filled with n-heptane as well. Thanks to the above strategy, optical distortion was completely avoided. The degree of image distortion was checked by inserting a ruler inside the column and by verifying the calibration between the real sizes and the sizes collected by the camera lens.

The behavior of the bubble column, namely the empty column without the SMX mixer inside, was analyzed as well. Data gathered from the bubble column revealed to be useful for 
a comparison with SMX static mixers. The column has a diameter of $16.2 \mathrm{~mm}$ and its height is $450 \mathrm{~mm}$. The $\mathrm{SMX}^{\mathrm{TM}}$ Sulzer geometry was employed in all the experimental analyses performed. The static mixers are constituted by an elementary unit, usually called element, which is repeated and rotated along the main axis. The number of mixer elements depends on the application of the device. Moreover, the number of mixer elements characterizes the device and has a considerable influence on its behavior (Singh et al. 2009).

Fig. 1 depicts one of the mixer structures used during the experiments. The device reported has 10 mixing elements. Mixers with 5 and 15 elements were examined as well. As presented in Fig. 1, each element is rotated by 90 degrees with respect to the previous one. Moreover, the elements are made by a series of inclined blades to 45 degrees from the axis. The standard SMX Sulzer presents some geometric constraints such as the unitary ratio of the element length over its diameter.

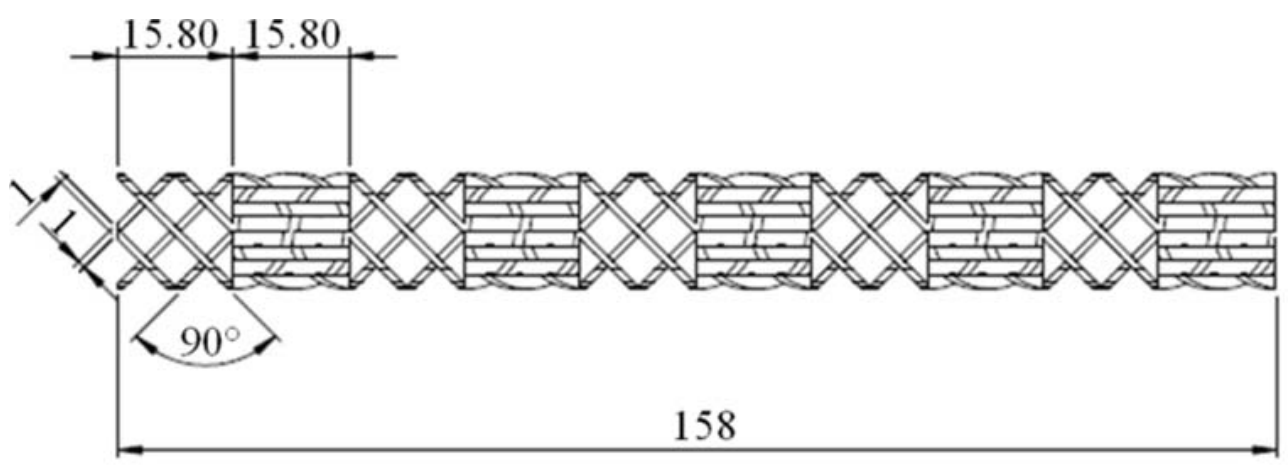

Fig. 1. Details of the 10 elements SMX static mixer. The length unit is mm.

The 5, 10 and 15 elements mixing devices investigated in the present work were created through 3D printing of CAD files in Accura ClearVue ${ }^{\mathrm{TM}}$ material. Thanks to this technique, it was possible to make fully transparent plastic SMX mixers. The Accura ClearVue ${ }^{\mathrm{TM}}$ refractive index is 1.5 whereas that of $n$-heptane is 1.39 . These values proved to be close enough to ensure satisfactory transparency for the optical visualization (cf. Fig. 9). These mixers present the same element dimensions, as shown in Fig. 1. The width (resp. thickness) 
of a single crossbar is $1.98 \mathrm{~mm}$ (resp. $1 \mathrm{~mm}$ ). The length and diameter of an element is 15.8 $\mathrm{mm}$. The ratio between diameter and length of an element is thus 1 , which conforms to the standard SMX definition (Liu et al. 2006; Singh et al. 2009). The 5, 10, 15 elements devices have an overall length of 79, 158 and $237 \mathrm{~mm}$ respectively. The distance between the top of the gas injector and the mixer was kept constant at $100 \mathrm{~mm}$ during all the tests. This space was largely enough for bubbles to reach their steady state rising velocity.

The nitrogen flow rate was controlled through an electronic valve connected to a flow regulator. The flow controller employed (Brooks Instrument Flow Controller) is accurate as the maximum potential error during the flow regulations is lower than $2 \%$. The effect of two different nozzle diameters was analyzed, namely $0.25 \mathrm{~mm}$ and $1 \mathrm{~mm}$. The nitrogen inlet pressure was settled and maintained to 2 bars using a pressure regulator valve.

\subsection{Measurement techniques}

The measurement methods adopted were the Backlight Shadowgraph Technique (BST) and the particle image velocimetry (PIV). The objective was to estimate the gas hold-up, the bubbles' sizes, shapes, paths and rising velocities inside the static mixer. The liquid velocity fields were quantified as well through the high-speed PIV. To estimate the gas hold-up, a series of images was collected with a very low frequency, namely $5 \mathrm{~Hz}$. The first frame of the series was acquired without gas. This first frame measured the initial state of the liquid level. Then, by injecting the gas, images with a higher liquid level were recorded. The presence of nitrogen bubbles within the system increases the overall liquid volume. This volume difference was estimated by comparing the first image with the others. The software imageJ® was employed to make the calibration and to estimate the increment of the liquid level. 


\subsubsection{The Particle Image Velocimetry}

Particle Image Velocimetry (PIV) is an optical and non-intrusive methodology to measure instantaneous flow velocities (Link et al. 2008). This technique is based on image processing of two consecutive frames acquired at a known time interval (Sathe et al. 2010). The PIV is commonly employed to examine liquid flow or gas-liquid flow (Sathe et al. 2010) even with relatively high gas holdup (Deen et al. 2002b; Liu et al. 2005; Kováts et al. 2017). In our PIV measurements, a method similar to that described in Deen et al. (2000) and Funfschilling and Li (2001) was used. In multiphase flows, the PIV shows certain limitations (Raffel et al. 1998; Funfschilling and Li 2001). Among them, the major limitations encountered in this study were the sedimentation of the seeding particles, and the shadows created by SMX and bubbles. Lastly, the light diffraction on the phase boundaries, SMX and column walls required the use of a specific strategy. The above limitations were partially resolved by employing suitable fluorescent seeding particles. The seeding particles used are fluorescently labelled polystyrene particles (PS-FluoRed). The tracer formation process generates polymer

particles with optimal properties such as high monodispersity, spherical shape, brilliant fluorescence and minimized dye leaching into the surrounding medium. These spherical particles have a diameter of $25.07 \mu \mathrm{m}$ with a standard deviation of $0.20 \mu \mathrm{m}$, their density is $1.05 \mathrm{~g} / \mathrm{cm}^{3}$, and their refractive index is 1.59 . Furthermore, they have the property to absorb the laser light with a wavelength of $532 \mathrm{~nm}$ and to emit it with a wavelength of $607 \mathrm{~nm}$. This specific property allowed us to use a filter to remove all of the reflected and scattered laser light from the static mixer, the column, and the bubbles. This filter allowed only the light with wavelength between $595 \mathrm{~nm}$ and $615 \mathrm{~nm}$ to reach the camera lens. The above strategy improved the quality of the investigation significantly. One major drawback of this tracer is its sedimentation velocity of up to $0.3 \mathrm{~mm} / \mathrm{s}$ estimated with the Stokes law (G. Stokes 1850). 
This value was confirmed by the PIV results as well. The corresponding Stokes' relaxation time is $89 \mu$ s for these seeding particles and can be considered suitable enough for the time scale during the PIV experiments.

The sedimentation drove us to remove the solution from the column at the end of each experiment. The solution containing the particles was then collected in a dedicated agitation system that ensured its homogeneity. This approach guaranteed reliable results and repeatability of experiments. The PIV images were acquired through a high-speed and highresolution camera, namely the FASTCAM SA-Z with 12-bit dynamic range and a resolution of $1024 \times 1024$ pixels. This camera is equipped with a highly light-sensitive image sensor (monochrome ISO 50,000). The high power diode pumped Nd:YAG Laser was employed in the PIV investigation. This is a dual oscillator head with a high repetition rate and an average power of $120 \mathrm{~W}$. Two different frequencies were used to perform data acquisition. The instantaneous flow velocities were acquired at $100 \mathrm{~Hz}$. The laser time pulse ranged from $2 \mathrm{~ms}$ to $8 \mathrm{~ms}$ (from $500 \mathrm{~Hz}$ to $125 \mathrm{~Hz}$ ) with a view to achieve the optimal displacement of the particles between the two consecutive frames required for the velocity field computation. The laser and the camera were connected via TTL inputs/outputs with a high efficiency synchronizer. The laser emits high-energy, monochromatic light with a wavelength of 532 $\mathrm{nm}$. For each configuration, namely with different gas superficial velocities, mixer length and diameter of the injector, 7500 flow fields were acquired in total and processed to obtain the averaged flow field. The 7500 fields were collected through 5 different repetition tests, each corresponding to 1500 flow fields. For each test, the solution containing the seeding particles was removed from the column and stirred for at least 2 minutes before reuse.

The pulsed light was converted into a laser sheet by using a series of curved mirrors and lenses. The laser sheet was focused in the middle section of the column, along the axial direction, and the lighted seeding particles located on this plane were then acquired by the 
camera. The laser sheet can be considered two-dimensional because of its small thickness in the orthogonal direction. The plane position and thickness in both sides of the jacket were checked daily and kept constant. The calibration, the distance between the camera lens and the column, and the relative position of both devices were controlled as well. To increase the quality and the resolution of acquisitions, the SMX mixers' elements were examined in groups of five. This decision represents a fair compromise between image quality and the number of elements visualized on each image. Data were collected and analyzed by DaVisLaVision ${ }^{\circledR}$ software. These PIV images were subdivided into small interrogation windows. The seeding particles' displacement within these windows were measured by crosscorrelation of two consecutive frames. The velocity fields were calculated from the time interval between the frames $(\Delta t)$ and the measured displacement. The adaptive PIV scheme was selected in order to achieve the suitable image treatment. The multi-pass option permitted to decrease progressively the investigation window size. The window ranged from $64 \times 64$ pixels to $8 \times 8$ pixels. The noise was removed by applying a Gaussian filter. The Davis posttreatment algorithm and image-filtering allowed proper phase discrimination: the bubbles were completely removed by the PIV raw images if they were located on the laser plane.

\subsubsection{The shadowgraph}

In addition to the PIV applied to the continuous liquid phase, the shadowgraph was implemented to achieve an accurate estimation of bubbles' sizes and velocities as a tracking technique for the dispersed phase. This method of analysis is frequently used to investigate dispersed systems characterized by high contrast between the phases (Settles 2001). The images acquisition setup used in the experiments is analogous to the one described by Laupsien et al. (2017). The technique is based on the shadows created by bubbles rising in the stagnant n-heptane. A EFFILUX LED panel was mounted behind the column as a light 
source. The distance between the panel and the column was $0.7 \mathrm{~m}$. The monochrome LED panel ensured a homogeneous lighting and provided a high illumination density (max 40001m). Particular care was given to the LED panel position, optimized to prevent any shadowing and reflection phenomena. Well-outlined shadows were created by the bubbles. The recording of these shadows was obtained by a high-speed camera located in front of the column. The same camera as for the PIV was employed. The lens was changed, and the filtering system removed. As previously mentioned, the cylindrical column produces a lens effect totally cancelled out by the surrounding square jacket filled with n-heptane. It is worth noting that the refractive indices of heptane, glass and the plastic material of the mixers are close to each other. The mixer and the column are thus almost invisible from outside the cubic box.

Photron-FASTCAM ${ }^{\circledR}$ enabled full control of the camera parameters, such as the frame acquisition rate, the image resolution, and the exposition time. The acquired images had a resolution of $256 \times 1024$ pixels, corresponding to $25 \times 100 \mathrm{~mm}$ (about $10.2 \mathrm{pixel} / \mathrm{mm}$ ). Although the camera employed was capable of acquiring up to one million frames per second, a frequency of $500 \mathrm{fps}$ was considered suitable for the shadowgraph investigation. In fact, this acquisition frequency permitted to obtain an optimal mean bubble displacement between two consecutive frames, corresponding to $0.1-0.2 \mathrm{~mm}$. Monitoring displacements below this range requires a higher acquisition frequency, leading to an increase of the amount of data recorded and it complicates post-processing. Higher frequency tests were conducted and led to the same results.

As for the PIV experiments, the shadowgraph tests of the SMX were conducted by splitting the elements into groups of five elements to achieve an optimal image resolution. To increase the reliability of the PIV and shadowgraph imaging technique, each experiment was repeated five times with five-minute intervals between them. An algorithm for the post- 
treatment of the images was implemented in Halcon ${ }^{\circledR}$. As the first step of the post-treatment, the background of the images was isolated and removed from each frame and the contrast between the liquid and gaseous phase was artificially increased. A threshold permitted us to isolate the bubbles. A region number was assigned to each bubble. Subsequently, the Halcon ${ }^{\circledR}$ 'operator elliptic_axis was chosen to estimate the bubbles' size and position. The operator elliptic_axis estimates the radii $R_{a}$ and $R_{b}$ and the orientation of the ellipse having the same aspect ratio of the input region. The optical_flow_mg operator with the FDRIG algorithm was employed to compute the optical flow between two images (Brox et al. 2004). This optical flow represents the movement between two consecutive images and allowed the estimation of the bubbles' velocities. The Halcon ${ }^{\circledR}$ algorithm is able to determine bubbles' velocities, formation frequency, position and shape.

\section{Results and discussion}

\subsection{Gas hold-up}

The gas hold-up experiments were conducted using both the plastic SMX mixers and the empty bubble column. Increments of the n-heptane level were measured once nitrogen bubbles were generated in the system. The initial liquid level $\left(h_{i}\right)$ and the expanded liquid level after gas injection $\left(h_{f}\right)$ were measured by analyzing the image sequences. Measure errors in locating the liquid head cannot be prevented because of its fluctuation. In fact, bubbles burst at the heptane surface and induced oscillations. To compensate for these perturbations, several images were acquired to average the liquid level. In order to assess reliable values of hold-up, repeated calibration was performed to obtain scale factor from pixel to $\mathrm{mm}$. At least 50 images were averaged to estimate the mean increment of liquid level. This number of 
frames was considered acceptable to estimate suitable mean values of the liquid level. The hold-up value revealed, in fact, to be unchanged by increasing the number of frames acquired. Experiments were repeated four times with similar results. The values of each experiment were obtained with the following equation 3.1. The liquid volume inside the column $\left(V_{L}\right)$ was measured and annotated before each test in order to double check the liquid volume values.

$$
\varepsilon_{g}=\frac{V_{g}}{V_{L}+V_{g}}=\frac{\left(h_{f}-h_{i}\right)\left(\pi \frac{d_{c}^{2}}{4}\right)}{h_{f}\left(\pi \frac{d_{c}^{2}}{4}\right)}
$$
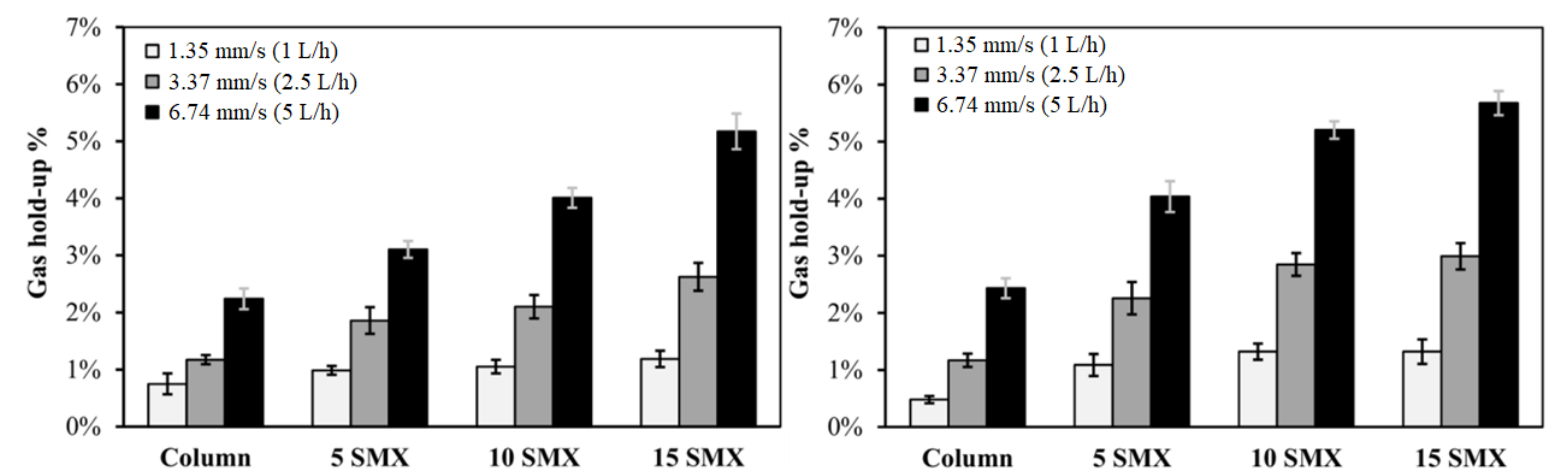

Fig. 2. Gas hold-up values for the $0.25 \mathrm{~mm}$ (left) and $1 \mathrm{~mm}$ (right) nozzle injectors.

Fig. 2 illustrates the main findings. The comparison of the hold-up values with and without static mixer shows a substantial increase caused by the presence of the mixing device. It is interesting to note that in all of the eighteen cases with the SMX, the hold-up is increased with respect to the simple bubble column. Error bars show the standard deviations and depict the variability among the performed experiments. The results achieved for the empty column match those expected. The values of hold-up detected for the $0.25 \mathrm{~mm}$ nozzle suggest that this smaller injector leads to smaller bubbles, then lower terminal velocities, higher residence time and then a higher hold-up of nitrogen. This was found to be true except for the higher 
superficial gas velocity. This uncommon behavior is mainly due to a transition of the bubbles' formation regime towards a jet regime.

Different considerations can be deducted from the data collected by employing the SMX mixers. The hold-up values resulting from the smaller nozzle $(d n=0.25 \mathrm{~mm})$ and lowest superficial gas velocity $\left(V_{s}=1.35 \mathrm{~mm} / \mathrm{s}\right)$ appear to be almost constant. A possible explanation for this peculiar behavior might arise from bubbles' sizes in these conditions. The small bubbles generated can potentially rise into the mixer more swiftly, without interacting with each other, except in the first elements of the device. The coalescence and breakup phenomena are restricted in these circumstances. Looking at all the other cases examined, we notice that the gas holdup increases with the number of elements. The larger nozzle diameter appears to increase the gas hold-up significantly, for all superficial gas velocities (see Fig. 2). Besides, the effect of the nozzle size on the gas hold-up cannot be neglected even by employing 15 elements. Nevertheless, an equilibrium between coalescence and breakup phenomena cannot be excluded particularly in the last elements of the mixer. These observations are further discussed in the next section.

\subsection{Particle Image Velocimetry results}

The PIV technique was employed to examine the liquid velocity fields in two configurations: the empty column and the column with the SMX. As reported in section 2.3. Measurement techniques, 7500 frames were acquired to enhance the accuracy of the results. The data obtained from the empty column led to the expected results. The velocity fields collected are well delineated: an up-flow was detected near the bubbles rising through the 
stagnant n-heptane, while a down-flow was measured near the column walls. This is confirmed by both the instantaneous and averaged liquid flow fields. Fig. 3 illustrates some velocity fields obtained by the PIV performed in the column without the SMX.
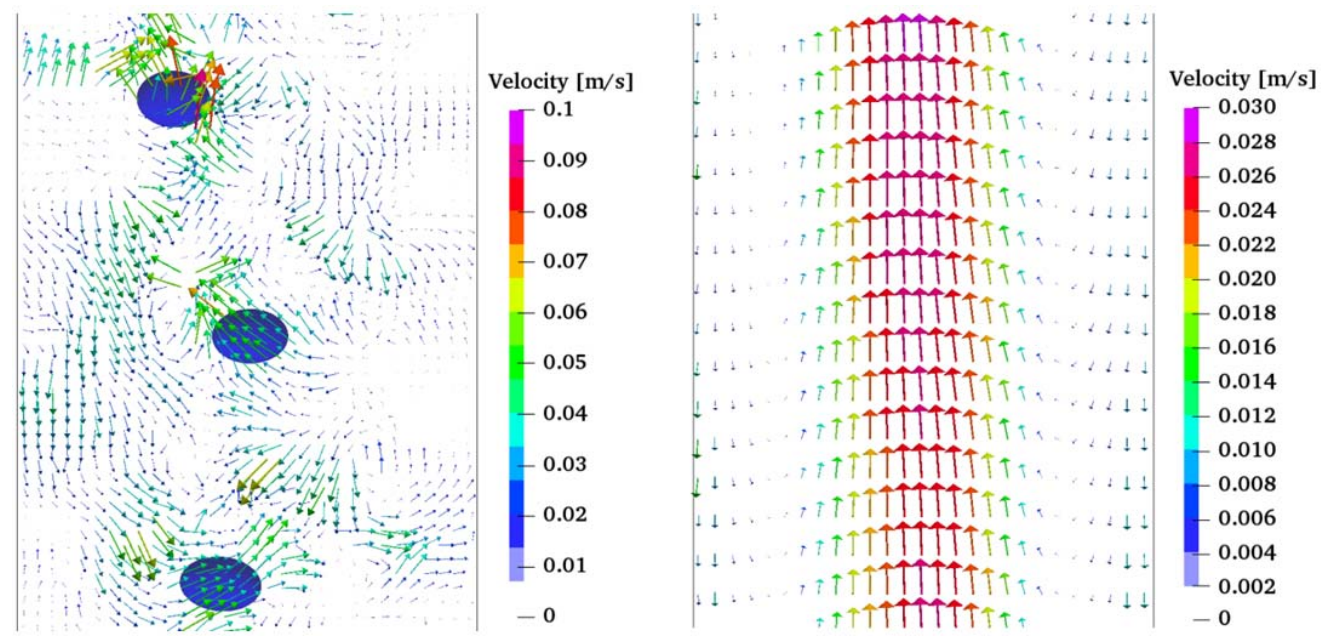

Fig. 3. PIV results in the simple column: instantaneous vector field colored by velocity magnitude (1.h.s.) and averaged vector field in the same column section (r.h.s.). Results obtained with $d n=1 \mathrm{~mm}$ and $V_{s}=1.35 \mathrm{~mm} / \mathrm{s}$.

The left picture displays the portion of the column examined in which both a PIV instantaneous velocity field and the bubbles can be seen. It should be noted that the bubbles and the liquid velocity flow field are overlapped in Fig. 3. Bubbles that are not crossed by the laser plane do not perturb the PIV measurement. In the case of Fig. 3, the two bubbles at the bottom were located behind the laser plane. The gas injecting system was located below the bottom of this image. On the right, the average flow field of the same region is illustrated. The averaged field in Fig. 3 reports a characteristic behavior of the system: the bubbles tend to pass through the column center. This result, confirmed by the shadowgraph technique, translates into a mean up-flow in the centerline. On the other hand, regions close to the column wall show a mean down-flow. The PIV results are completely different when the 
SMX mixers are used. For example, Fig. 4 and Fig. 5 illustrate an instantaneous velocity field measured inside the SMX.
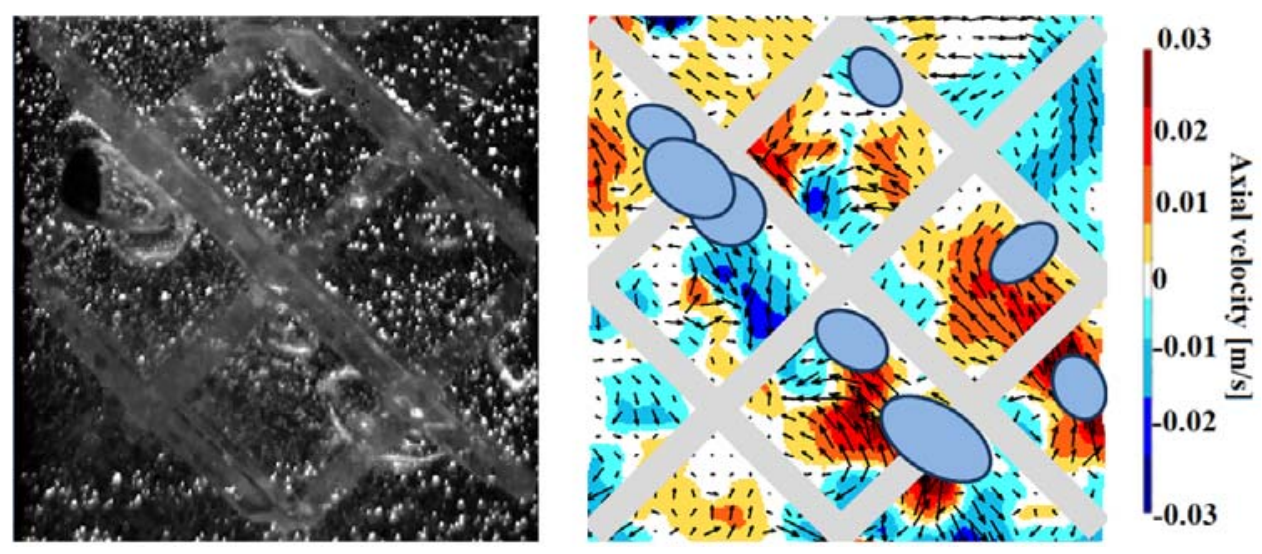

Fig. 4. Raw PIV image and instantaneous flow field in the first SMX element (colored by axial component of velocity). $d n=0.25 \mathrm{~mm} . V_{s}=1.35 \mathrm{~mm} / \mathrm{s}$.

The motion of the liquid phase due to a bubble passage can be identified by looking scrupulously at the picture on the right of Fig. 4, where the bubbles' shapes are reported as well. For instance, an up-flow was observed in proximity of the three rightmost bubbles. Some velocity fields, however, may not match the expected mid cutting plane pattern through a bubble as in the case of the leftmost bubbles. This is due to the fact that the cutting plane of Fig. 4 is shifted along the third direction with respect to the bubbles' mid centerline plane. Flow patterns become more complicated to interpret for larger gas superficial velocities due to the presence of numerous bubbles. Indeed, the lower superficial gas velocity employed, namely $1.35 \mathrm{~mm} / \mathrm{s}$, allowed to isolate the bubbles. The main liquid flows were located in the zone of bubbles' passage. Up-flows were generally observed in the bubbles' proximity, in front of a bubble and in its wake, when looking in a median cutting plane of the bubble. Down-flows were usually encountered in the lateral sides of the bubbles' paths. We observed a reduction of the velocities, due to lower bubbles velocities inside the mixer. The bubbles 
velocities are approximately 2 or 3 times smaller inside the mixer. The PIV results suggest that the bubbles rise in the wake left by the previous ones. This behavior implies some preferential paths in the SMX static mixer. It is worth mentioning that in Fig. 5 the flow field is quite scarce in the upper part of the static mixer (r.h.s) due to the presence of several bubbles in this zone (1.h.s). The gas-liquid interfaces of bubbles reflect the laser, making the tracking of seeding particles difficult.

The high acquisition frequency allowed to detect rapid phenomena like bubble deformation and break-up. On the other hand, the findings in this study are subject to some limitations. Firstly, the PIV technique is only 2D planar. Furthermore, it was not possible to collect data in the regions close to the SMX elements' bars and in the regions characterized by high values of local hold-up. In fact, the quality of PIV results decreases with the amount of bubbles. The presence of bubbles creates black zones and shadows. In these areas, it was often complicated to measure the flow field. This is a well-known problem of the PIV measurements in multiphase flows (Funfschilling and Li 2001). The DaVis-LaVision ${ }^{\circledR}$ software permitted a preprocessing of the raw PIV images capable to remove the bubbles interference and to enhance the light emitted by the particles, namely by filtering and normalizing the pixels intensity. This approach allowed us to partially solve the problem related to the local increment of the gas hold-up. 

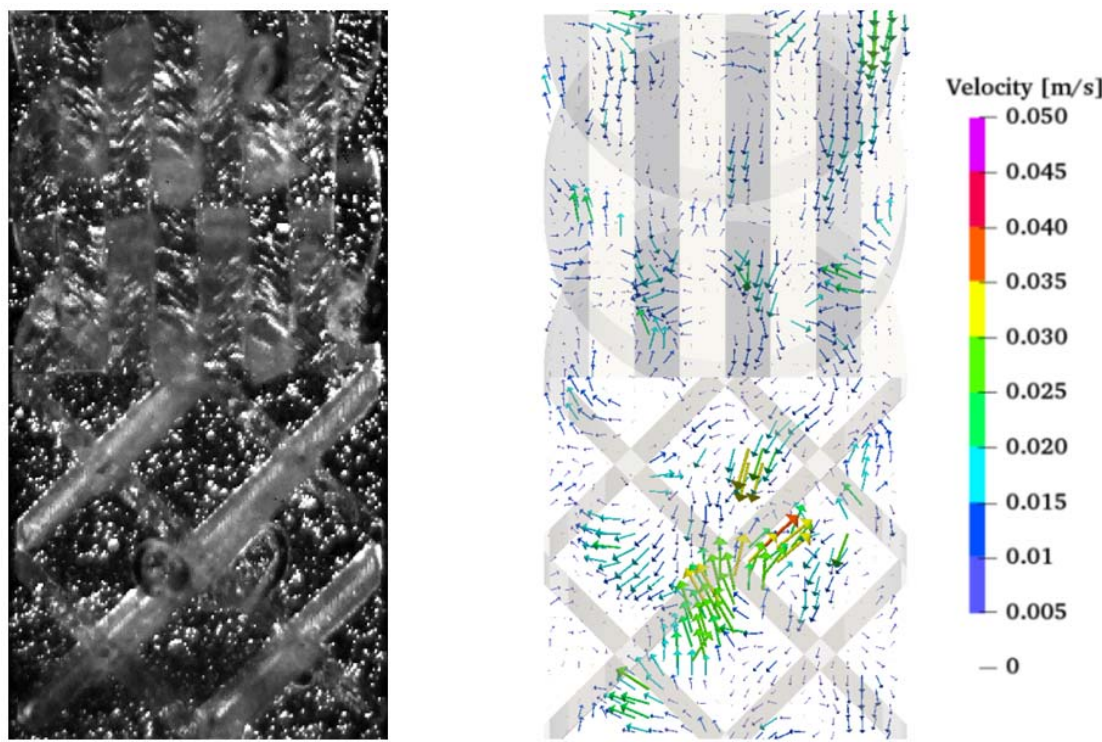

Fig. 5. Raw PIV acquisition in the first 2 elements of the 10 elements device (1.h.s.) and corresponding instantaneous vector field colored by velocity magnitude (r.h.s.). Results obtained with $d n=1 \mathrm{~mm}, V_{s}=1.35 \mathrm{~mm} / \mathrm{s}$.

The results from the empty column and the SMX mixer were further compared in order to reveal the effect of the mixing device. We split the velocity vector into two components along the horizontal $(V x)$ and upward vertical $(V y)$ directions in order to simplify the following discussions. The horizontal $(V x)$ and vertical $(V y)$ liquid velocities' probability distributions found for $V_{s}=3.37 \mathrm{~mm} / \mathrm{s}$ are reported in Fig. 6 and Fig. 7. The possible interference of the particles' sedimentation velocity was removed from the data by subtracting the sedimentation velocity from the vertical components $(V y)$. 

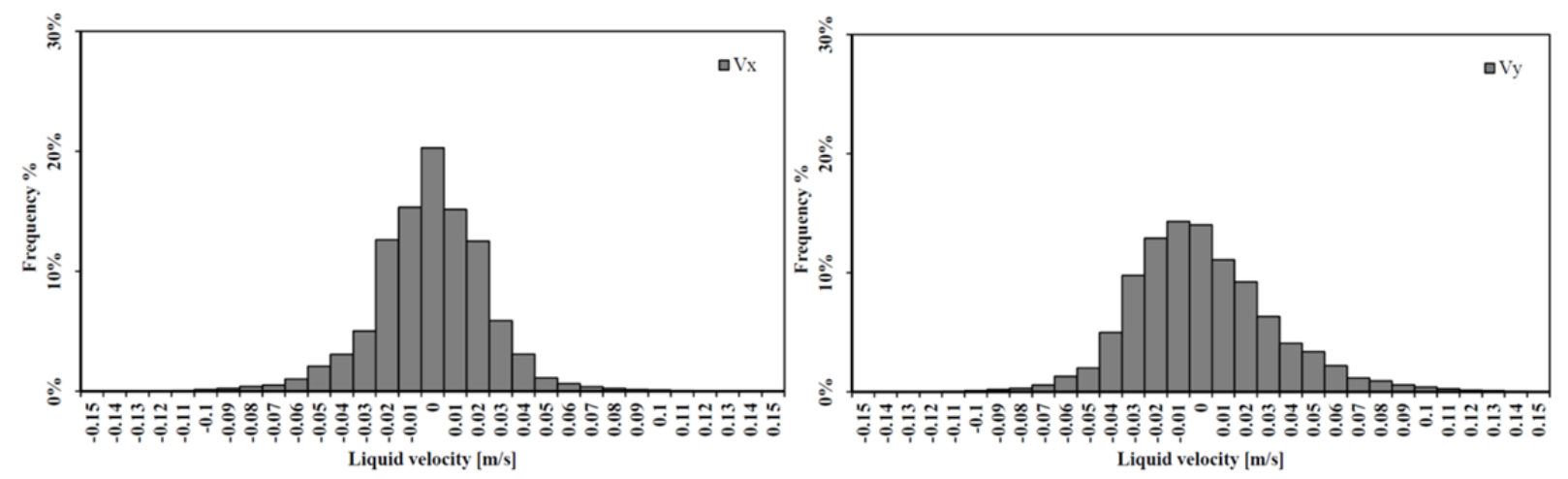

Fig. 6. Liquid velocities distributions measured in the $x$-axis component (left) and y-axis component (right) in the column without SMX. $d n=0.25 \mathrm{~mm} . V_{s}=3.37 \mathrm{~mm} / \mathrm{s}$.

The vertical liquid velocities decreased significantly in favor of horizontal velocities in the SMX mixer. The maximum magnitude of the liquid velocities detected inside the static mixer were between $10 \mathrm{~cm} / \mathrm{s}\left(V_{s}=1.35 \mathrm{~mm} / \mathrm{s}\right)$ and $15 \mathrm{~cm} / \mathrm{s}\left(V_{s}=3.37 \mathrm{~mm} / \mathrm{s}\right)$. However, the percentages of high velocities were much lower when the mixer is used than in an empty bubble column. As expected, velocities in the empty bubble column were found to be inherently related to the bubble rising velocities, with maxima of approximately $20 \mathrm{~cm} / \mathrm{s}$. Velocities higher than $0.15 \mathrm{~m} / \mathrm{s}$ and lower than $-0.15 \mathrm{~m} / \mathrm{s}$ were neglected. However, they represent less than the $0.1 \%$ (resp. $0.05 \%$ ) for the empty column.

The histogram of vertical velocity component on the right is more spread than the horizontal components histogram, which means that higher axial velocity components $(V y)$ were obtained. The probability distribution of the horizontal component $(V x)$ of the velocities is fully symmetric. Fig. 7 depicts the distribution of liquid velocities found inside the 10 elements mixer. We noted several differences compared to the empty column. They can be explained partly by the particular geometry of the SMX. The $45^{\circ}$ bars divert the bubbles' paths, thus causing changes in the velocities of the liquid phase. 

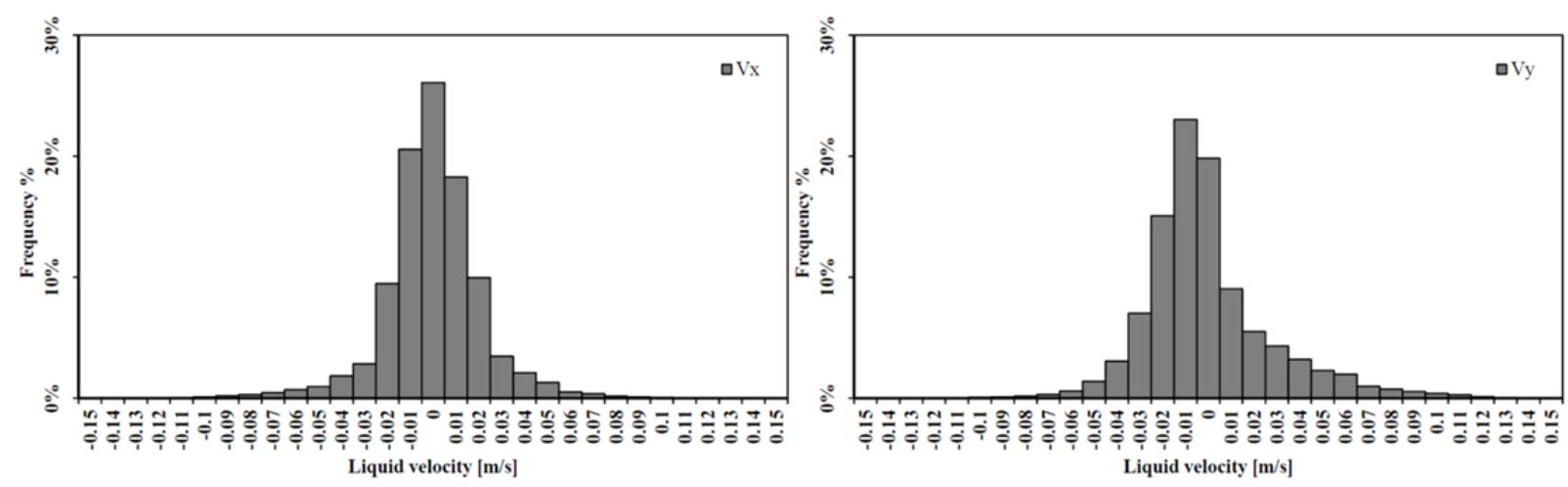

Fig. 7. Liquid velocities distributions measured by the PIV in the $x$-axis component (left) and y-axis component (right) in the column with SMX. $d n=0.25 \mathrm{~mm} . V_{s}=3.37 \mathrm{~mm} / \mathrm{s}$.

The distributions present a maximum around zero velocity due to the stagnant liquid operating conditions. When comparing Fig. 6 with Fig. 7, we note that the axial component was more affected by the presence of the mixer. The Standard Deviation changed by $18.3 \%$ for the horizontal components of the velocity histogram and by $26.5 \%$ for the vertical. It can thus be stated that the presence of the SMX decreases both components of the velocity however in an unequal measure. The volumetric flow rate $Q v$ computed as equation 3.2 was null in several cross sections of the column.

$$
Q v=\iint_{S}(\vec{V} \cdot \vec{n}) d S
$$

\subsection{Shadowgraph results}

The relatively low surface tension between the two phases makes the shadowgraph investigation more interesting because of the higher amount of coalescence and break-up events. To assess the shape and rising velocity of the bubbles, the backlight shadowgraph technique was employed. The number of events collected and examined, ranging from 70000 to 100000 , was considered large enough to estimate the mean properties of the system (Buffo 
and Alopaeus 2016). The bubble diameter was estimated by applying the hypothesis that bubbles are shaped as ellipsoids (Grund et al. 1992; Lage and Espósito 1999; Bouaifi et al. 2001; Kazakis et al. 2008). Based on this assumption, an equivalent bubble diameter can be estimated. This diameter is defined as the diameter of the sphere whose volume is equivalent to the ellipsoidal bubble volume (Lage and Espósito 1999). This hypothesis was later verified. The amount of gas contained throughout the system with and without static mixers was recomputed by summing up the volumes of all the bubbles. These integrated values were found comparable with the experimental values reported in the section 3.1. Gas hold-up. The maximal deviation observed is lower than $5 \%$. This dissimilarity could be attributed to the ellipsoidal assumption made about bubbles shapes. The satisfactory comparison between these two different methods reveals the accuracy of the images post-treatment algorithm implemented in Halcon ${ }^{\circledR}$ and Matlab ${ }^{\circledR}$. The Halcon ${ }^{\circledR}$ treatment has proven to be robust and efficient as it was able to detect more than $95 \%$ of the bubbles.

A first set of images was collected to examine the characteristics of bubbles flowing in the empty column. When comparing the bubbles' shapes and velocities in the empty column with the ones detected before the SMX, no significant difference was identified. This suggests that the mixer does not affect the bubble shape and velocity in the upstream region. This observation remains valid in regions far from the SMX, roughly larger than two-cylinder diameters. Fig. 8 provides the density probability distributions of the bubbles' diameter for certain operating conditions in the simple column without a mixing device and at the outlet of the SMX.

From the first plot illustrated in Fig. 8 (a), it can be seen that the distribution obtained using the bigger nozzle is quite narrow around the Sauter diameter. The distribution resulting from $d n=0.25 \mathrm{~mm}$ and $V_{s}=3.37 \mathrm{~mm} / \mathrm{s}$ presents a different trend, with a secondary peak corresponding to small bubbles (de about $0.8 \mathrm{~mm}$ ). This is explained by a different 
detachment regime for the bubbles. It was not possible to predict bubbles' characteristics for the higher gas superficial velocity due to overlaps of bubbles that prevent estimating their diameter.

The equivalent bubble diameters were also measured after the outlet of the static mixers. As shown in Fig. 8, the bubble distributions changed considerably at the mixer exit of the three devices, when compared to Fig. 8 (a). The overall distributions are generally wider. The percentages of small bubbles $(d e<1 \mathrm{~mm})$ as well as large bubbles (de $>4 \mathrm{~mm})$ changed markedly. The most striking changes were observed for the bigger nozzle. The smallest bubbles generated by the smaller nozzle $(d n=0.25 \mathrm{~mm})$ tended to coalesce when passing through the mixer. The breakup phenomena were more restricted in these circumstances. The frequency distribution histogram resulting from the $1 \mathrm{~mm}$ nozzle reported in Fig. 8 (b) shows a significant primacy of coalescence phenomena. A peculiar trend should be noted for this distribution, as a peak is detected in proximity of $0.5 \mathrm{~mm}$. These small bubbles were generated mainly during the impact with the SMX first element. In fact, the bubbles have bigger diameters before entering the mixer $\left(d_{32}=3.05 \mathrm{~mm}\right)$ and hence higher velocities. This translates to high break-up probability. The Sauter diameters detected at the exit of the 5 elements are clearly affected by the injector sizes. Fig. 8 (c) provides the bubble size distributions measured at the 10 SMX outlet. These distributions present some changes for both nozzles when compared with the previous ones. The histogram for the $0.25 \mathrm{~mm}$ nozzle is more spread, which signifies that more bubbles broke-up and/or merged. However, concerning the $1 \mathrm{~mm}$ nozzle histogram, the changes are less obvious. Besides, the Sauter diameters are almost identical.

The data in Fig. 8 (d) show the equivalent diameter distributions observed after the 15 elements device. The size distributions for the $0.25 \mathrm{~mm}$ and $1 \mathrm{~mm}$ nozzles are now similar to each other. These results tend to prove that a dynamical equilibrium is reached inside the 15 
elements static mixer. This equilibrium results from the dynamic competition between the coalescence and break-up phenomena involved in the mixer. The Sauter diameters depend much less on the nozzle, and they measure approximately $2.5 \mathrm{~mm}$. 


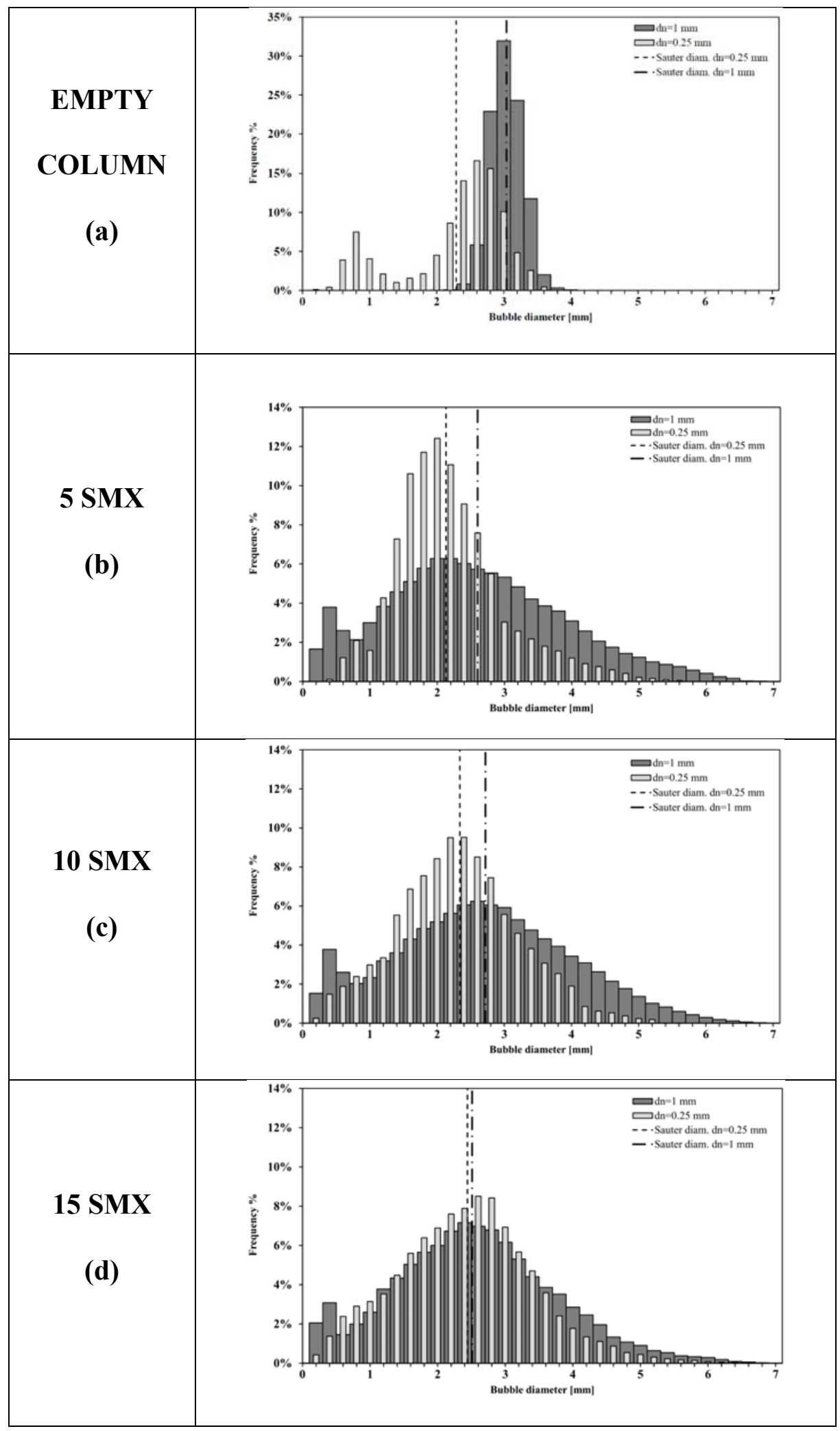

Fig. 8. Equivalent diameter distributions measured under different operating conditions: a) empty column, b) outlet of the 5 elements, c) outlet of the 10 elements, d) outlet of the 15 elements. $V_{s}=3.37 \mathrm{~mm} / \mathrm{s}$. 
Zigzag and/or spiral bubble paths were often observed in the experiments. A statistical analysis of the probability to find bubbles throughout the system was performed by analysing the instantaneous images. The results obtained on the column without SMX revealed that the probability of finding a bubble in the centre of the column is higher than near the walls. These results are consistent with those of other studies (Saffman 1956; Clift et al. 1978; Lunde and Perkins 1998). An identical analysis was performed for the 5, 10 and 15 elements SMX.

Since other SMX lengths lead to similar data, Fig. 9 shows only the 10 elements results. Compared to the bubble column, the instantaneous and mean probabilities of finding bubbles inside the mixing device are higher. The static mixer is decreasing the bubbles velocities and is therefore increasing their residence time. Another observation emerges from the images of Fig. 9: the bubbles rise in the SMX by following preferential paths. These preferential paths are mainly close to the mixer-inclined bars. Furthermore, zones with a null probability (lower than $0.5 \%$ ) of finding bubbles can be distinguished (white regions). Down-flows were confirmed in these zones by the PIV technique. 



Fig. 9. Shadowgraph acquisitions and respective bubble occurrence probability detected in the 10 elements SMX fed by $d n: 0.25 \mathrm{~mm}$ (left) and $d n: 1 \mathrm{~mm}$ (right).

\subsection{Discussion and validation of optical methods}

Both the PIV and the shadowgraph results provide new insight into the two-phase flow pattern inside the static mixer. As shown in Fig. 10, the PIV findings match those observed in the shadowgraph. Up-flows were observed in high probability zones of bubbles passages. On the other hand, down-flows were recorded in low probability areas. The first element of the static mixer was considered appropriate to make this comparison because of its lower measurement errors. 


\begin{tabular}{|l|l|l|l|}
\hline Shadowgraph (a) & Bubbles occurrence (b) & PIV field (c) & Velocity profile (d) \\
\hline
\end{tabular}

Fig. 10. Detailed views of the $1^{\text {st }} \mathrm{SMX}$ element. $d n: 1 \mathrm{~mm} . V_{s}=1.35 \mathrm{~mm} / \mathrm{s}$. From left to right: a) Instantaneous bubble image, b) Bubble mean occurrence c) Mean PIV velocity field d) Mean vertical velocity profile $(V y)$.

The mean flow velocity of bubbles inside the empty column and the mixer is an important parameter since knowledge of it permits the evaluation of the gas residence time. The bubble velocities were evaluated through the shadowgraph results by tracking the bubbles' position in time. For example, the histograms showing the frequency distribution of the vertical velocity component $(V y)$ resulting from the empty column and the 10 elements SMX are reported in Fig. 11 as well as the mean axial velocity values. For the column without SMX, the probability distribution follows a normal distribution.
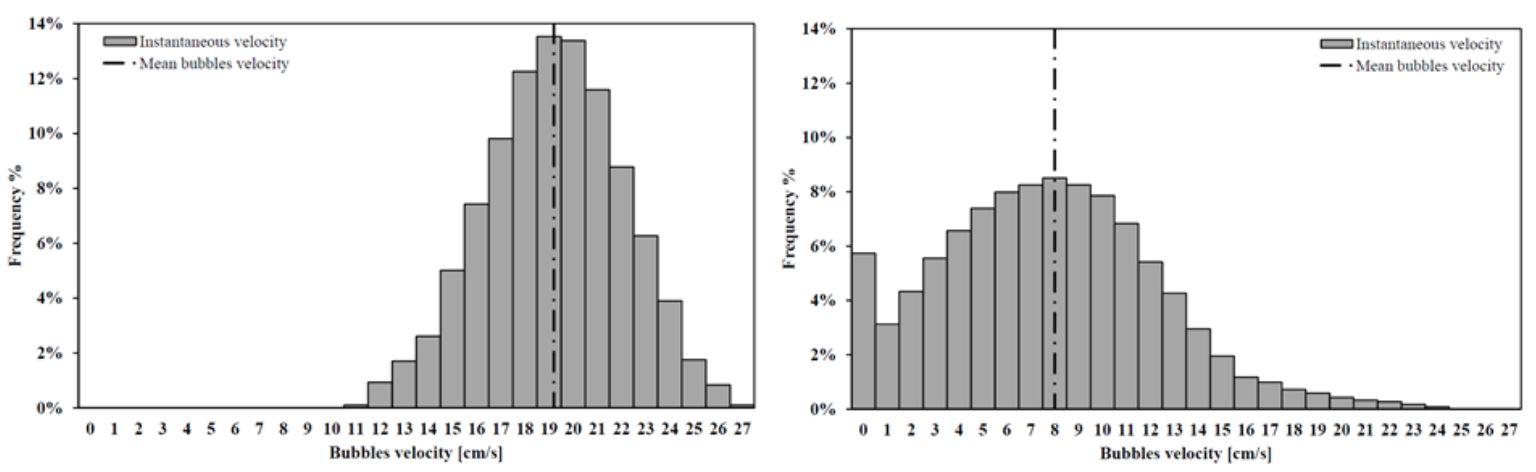

Fig. 11. Vertical velocity components $(V y)$ distributions in the simple bubble column (left) and in the 10 elements $\operatorname{SMX}$ (right). $d n=1 \mathrm{~mm} . V_{s}=1.35 \mathrm{~mm} / \mathrm{s}$. 
Velocities were obtained by tracking the bubble displacement every $0.02 \mathrm{~s}$. This short time interval was required in order to limit errors in the post-treatment process. The wide distribution may be due to both the oscillation of bubble shape and trajectory. In fact, the zigzag and spiral rising causes shape deformation and velocity instability. It is widely documented that the continuous changes of the bubble shape significantly affect the rising velocity (Saffman 1956; Mougin and Magnaudet 2001; Tripathi et al. 2015). The bubbles' velocities evolved considerably when the SMX was employed. The histogram of the frequency distribution of vertical velocity components is significantly altered as outlined in Fig. 11 (r.h.s.).

The instantaneous bubbles' velocities inside the mixer are scattered over the range 0-24 $\mathrm{cm} / \mathrm{s}$. Bubble overlap phenomena in the SMX mixer introduced measurement errors especially for the estimation of the velocities under high gas superficial velocities. The mean axial velocity detected inside the SMX is about $8 \mathrm{~cm} / \mathrm{s}(d n=1 \mathrm{~mm} . V s=1.35 \mathrm{~mm} / \mathrm{s})$. A similar value was found for the horizontal component of the velocity in all of the elements facing the camera. The mean velocity in the first element $(12 \mathrm{~cm} / \mathrm{s})$ is relatively higher than the others. Furthermore, no relevant changes of bubbles' mean velocity were observed inside the mixer after the third element.

A considerable amount of bubbles shows negligible velocity. These null values were mainly detected in proximity to the SMX crossbars. There are several possible explanations for this behavior. Firstly, the gap between the bars might be smaller than the bubble diameter, acting therefore as an obstacle. Furthermore, the space available decreases in some specific regions such as those at the connections between two consecutive elements. The energy required for the bubbles' deformation significantly affects the velocities.

A comparison between the measured velocity of the bubbles and those estimated by an empirical correlation was done. Various correlations for bubble rising velocity under different 
operating conditions are available in the literature (Harmathy 1960; Mendelson 1967; Wallis 1974; Tomiyama et al. 1998; Raymond and Rosant 2000; Tomiyama 2002). Tomiyama (2002) proposed a correlation that allows the calculation of the terminal velocity for a distorted oblate spheroidal bubble:

$$
V_{T}=\frac{\sin ^{-1} \sqrt{1-E^{2}}-E \sqrt{1-E^{2}}}{1-E^{2}} \sqrt{\frac{\left(\rho_{L}-\rho_{G}\right) g d_{b}}{2 \rho_{L}} \frac{E^{2 / 3}}{1-E^{2}}+\frac{8 \sigma}{\rho_{L} d} E^{4 / 3}}
$$

In this correlation, only valid for oblate spheroids, the terminal velocity $V_{T}$ depends on the bubble diameter $d_{b}$, the fluid properties and the aspect ratio $E$ less than 1 . The aspect ratio is defined as the ratio of the polar lengths to equatorial lengths. The bubbles' aspect ratio was estimated in order to evaluate the terminal velocity for our experiments. The post-processing of the shadowgraph acquisitions revealed that the value of mean vertical velocity in the empty column is about $19 \mathrm{~cm} / \mathrm{s}$ when the $1 \mathrm{~mm}$ nozzle is used. This value is close to $19.5 \mathrm{~cm} / \mathrm{s}$ estimated by to the above empirical correlation. Switching from the $1 \mathrm{~mm}$ to the $0.25 \mathrm{~mm}$ nozzle, the bubbles mean axial velocity decreased to $17.3 \mathrm{~cm} / \mathrm{s}$, relatively close to $17.6 \mathrm{~cm} / \mathrm{s}$ from the correlation of Tomiyama (2002).

As aforementioned, the rising velocity of bubbles allowed the estimation of their mean residence time. The minimum distance travelled by a bubble was measured by assuming its passage on the shortest path possible, namely moving with a straight path along the axial direction. The bubbles' velocities and their rising path length allowed us to determine the mean residence time under various operating conditions. The findings suggest that the mixer enhances at least twice the mean residence time. The formation frequency of bubbles was also calculated by recording the nozzle area. The major results are gathered in Table 1. It should be noted that the presence of the static mixer inside the column does not affect the bubble 
formation frequency. The formation frequency of bubbles and the flow rate permits the estimation of the bubbles mean diameters. The diameters estimated by the bubbles' shadows are reported in the last column. The maximum deviation is less than $15 \%$.

Table 1: Bubbles characteristics obtained by the post-treatment of the shadowgraph images.

\begin{tabular}{|c|c|c|c|c|}
\hline $\begin{array}{c}\text { Nozzle } \\
\text { diameter } \\
{[\mathbf{m m}]}\end{array}$ & $\begin{array}{c}\text { Superficial } \\
\text { gas velocity } \\
{[\mathbf{m m} / \mathbf{s}]}\end{array}$ & $\begin{array}{c}\text { Frequency } \\
\text { formation } \\
{[\text { bubbles/s] }}\end{array}$ & $\begin{array}{c}\text { Calculated } \\
\text { diameters } \\
{[\mathbf{m m}]}\end{array}$ & $\begin{array}{c}\text { Shadows } \\
\text { estimated } \\
\text { diameters [mm] }\end{array}$ \\
\hline 0.25 & 1.35 & 68 & 1.98 & 1.91 \\
\hline 0.25 & 3.37 & 89 & 2.45 & 2.17 \\
\hline 1 & 1.35 & 25 & 2.76 & 2.70 \\
\hline 1 & 3.37 & 45 & 3.09 & 3.05 \\
\hline
\end{tabular}

\section{Conclusion}

The main goal of the present work was to characterize the two-phase hydrodynamics in Sulzer SMX ${ }^{\mathrm{TM}}$ static mixers with different lengths. The experimental investigation was performed by bubbling nitrogen in stagnant liquid normal-heptane under various operating conditions: different superficial gas velocities, different mixer lengths and two nozzle sizes. The bubbles' sizes, shapes, velocities and positions were quantified. An image postprocessing was implemented to estimate the mean Sauter diameter of the bubbles at inlet and outlet of the SMX mixers. The capability to predict the real sizes, the shapes and velocities of bubbles was verified by conducting several comparisons with empirical correlations and data 
reported in the literature. The liquid velocities were measured by the PIV technique for the first time owing to the transparent 3D printing.

The obtained results reveal that the SMX substantially increases the gas hold-up and the residence time of bubbles. An increase of coalescence and breakup phenomena was observed at high hold-up value under the highest gas superficial velocity. The second major finding was the existence of preferential paths inside the mixer. This could potentially affect the mass transfer throughout the device. Furthermore, this study suggests that the 15 elements SMX is long enough to ensure a dynamic equilibrium between the coalescence and break-up of bubbles flowing through the device. The static mixer exhibited a viable effectiveness in the redistribution of bubble sizes and positions passing across the mixer. Although the coalescence phenomena in the mixer can lead to large bubbles, a considerable percentage of small-scale bubbles (diameter smaller than $0.5 \mathrm{~mm}$ ) was detected. In future investigations, it might be possible to use the experimental approaches presented in this work in order to collect further data, focusing on bubble breakup and coalescence phenomena. 


\section{Caption of figures}

Fig. 1. Details of the 10 elements SMX static mixer. The length unit is mm. 8

Fig. 2. Gas hold-up values for the $0.25 \mathrm{~mm}$ (left) and $1 \mathrm{~mm}$ (right) nozzle injectors. 15

Fig. 3. PIV results in the simple column: instantaneous vector field colored by velocity magnitude (1.h.s.) and averaged vector field in the same column section (r.h.s.). Results obtained with $d n=1 \mathrm{~mm}$ and $V_{s}=1.35 \mathrm{~mm} / \mathrm{s}$.

Fig. 4. Raw PIV image and instantaneous flow field in the first SMX element (colored by axial component of velocity). $d n=0.25 \mathrm{~mm} . V_{s}=1.35 \mathrm{~mm} / \mathrm{s}$

Fig. 5. Raw PIV acquisition in the first 2 elements of the 10 elements device (1.h.s.) and corresponding instantaneous vector field colored by velocity magnitude (r.h.s.). Results obtained with $d n=1 \mathrm{~mm}, V_{s}=1.35 \mathrm{~mm} / \mathrm{s}$. 20

Fig. 6. Liquid velocities distributions detected by the measurement in the $x$-axis component (left) and y-axis component (right) in the column without SMX. $d n=0.25 \mathrm{~mm}$. $V_{s}=3.37 \mathrm{~mm} / \mathrm{s}$.

Fig. 7. Liquid velocities distributions detected by the PIV measurement in the x-axis component (left) and y-axis component (right) in the column with SMX. $d n=0.25 \mathrm{~mm}$. $V_{s}=3.37 \mathrm{~mm} / \mathrm{s}$.

Fig. 8. Equivalent diameter distributions measured in different operating conditions: a) empty column, b) outlet of the 5 elements, c) outlet of the 10 elements, d) outlet of the 15 elements. $V_{s}=3.37 \mathrm{~mm} / \mathrm{s}$. 26

Fig. 9. Shadowgraph acquisitions and respective bubble occurrence probability detected in the 10 elements SMX fed by $d n: 0.25 \mathrm{~mm}$ (left) and $d n: 1 \mathrm{~mm}$ (right). 28 
Fig. 10. Detailed views of the $1^{\text {st }} \mathrm{SMX}$ element. $d n: 1 \mathrm{~mm} . V_{s}=1.35 \mathrm{~mm} / \mathrm{s}$. From left to right: a) Instantaneous bubble image, b) Bubble mean occurrence c) Mean PIV velocity field d) Mean vertical velocity profile $(V y)$

Fig. 11. Vertical velocity components (Vy) distributions in the simple bubble column (left) and in the 10 elements SMX (right). $d n=1 \mathrm{~mm} . V_{s}=1.35 \mathrm{~mm} / \mathrm{s}$. 29

\section{Caption of table}

Table 1. Bubbles characteristics obtained by the post-treatment of the shadowgraph images. 


\section{Publication bibliography}

Al Taweel, A. M., Yan, J., Azizi, F., Odedra, D., Gomaa, H. G. (2005): Using in-line static mixers to intensify gas-liquid mass transfer processes. Chemical Engineering Science 60 (22), 6378-6390.

Alekseev, K. A., Mukhametzyanova, A. G., D’yakonov, G. S. (2017): Experimental investigations of velocity fields in packed bed static mixers. Theoretical Foundations of Chemical Engineering 51 (3), 266-273.

Ayati, A. A., Kolaas, J., Jensen, A., Johnson, G. W. (2015): Combined simultaneous twophase PIV and interface elevation measurements in stratified gas/liquid pipe flow. International Journal of Multiphase Flow 74, 45-58.

Bouaifi, M., Hebrard, G., Bastoul, D., Roustan, M. (2001): A comparative study of gas holdup, bubble size, interfacial area and mass transfer coefficients in stirred gas-liquid reactors and bubble columns. Chemical Engineering and Processing: Process Intensification 40 (2), 97-111.

Boyer, C., Duquenne, A.-M., Wild, G. (2002): Measuring techniques in gas-liquid and gasliquid-solid reactors. Chemical Engineering Science 57 (16), 3185-3215.

Brox, T., Bruhn, A., Papenberg, N., Weickert, J. (2004): High Accuracy Optical Flow Estimation Based on a Theory for Warping. Proceedings of the European Conference on Computer Vision (ECCV) 3024.

Buffo, A., Alopaeus, V. (2016): Experimental determination of size distributions. Analyzing proper sample sizes. Measurement Science and Technology 27 (4), 45301.

Byrde, O., Sawley, M.L (1999): Optimization of a Kenics static mixer for non-creeping flow conditions. Chemical Engineering Journal 72 (2), 163-169.

Chen, R. C., Fan, L. S. (1992): Particle Image Velocimetry for Characterizing the Flow Structure in Three-dimensional Gas-Liquid-Solid Fluidized Beds. Chemical Engineering Science 47 (13/14), 3615-3622.

Chisti, Y., Kasper, M., Moo-Young, M. (1990): Mass transfer in external-loop airlift bioreactors using static mixers. Canadian Journal of Chemical Engineering 68 (1), 45-50.

Clift, R., Grace, J. R., Weber, M. E. (1978): Bubbles, drop and particles. New York: Academic Press.

Das, M. D., Hrymak, A. N., Baird, M. H.I. (2013): Laminar liquid-liquid dispersion in the SMX static mixer. In Chemical Engineering Science 101, 329-344.

Deen, N. G., Hjertager, B., Solberg, T. (2000): Comparison of PIV and LDA Measurement Methods Applied to the Gas-Liquid Flow in a Bubble Column. 10th Int Symp on Application of Laser Techniques to Fluid Mechanics.

Deen, N. G., Solberg, T., Hjertager, B. (2002a): Flow Generated by an Aerated Rushton Impeller. Two-Phase PIV Experiments and Numerical Simulations. Canadian Journal of Chemical Engineering 80, 1-15.

Deen, N. G., Westerweel, J., Delnoij, E. (2002b): Two-Phase PIV in Bubbly Flows. Status and Trends. Chemical Engineering \& Technology 25, 97-101 
Deen, N. G., Willems, P., van Sint Annaland, M., Kuipers, J. A. M., Lammertink, R. G. H., Kemperman, A. J. B. et al. (2010): On image pre-processing for PIV of single- and two-phase flows over reflecting objects. Experiments in Fluids 49 (2), 525-530.

Delnoij, E., Kuipers, J.A.M, van Swaaij, W.P.M, Westerweel, J. (2000): Measurement of gasliquid two-phase flow in bubble columns using ensemble correlation PIV. Chemical Engineering Science 55 (17), 3385-3395.

Delnoij, E., Westerweel, J., Deen, N. G., Kuipers, J.A.M., van Swaaij, W.P.M. (1999): Ensemble correlation PIV applied to bubble plumes rising in a bubble column. Chemical Engineering Science 54 (21), 5159-5171.

Engel, V., Stichlmeir, J., Geipel, W. (2001): Fluid Dynamics of Packings for Gas-Liquid Contactors. Chemical Engineering \& Technology 24, 459-462.

Fradette, L., Li, H. Z., Choplin, L., Tanguy, P. (2006): Gas/liquid dispersions with a SMX static mixer in the laminar regime. Chemical Engineering Science 61 (11), 3506-3518.

Funfschilling, D., Li, H. Z. (2001): Flow of non-Newtonian fluids around bubbles. PIV measurements and birefringence visualisation. Chemical Engineering Science 56 (3), 11371141.

G. Stokes, G. (1850): On the Effect of Internal Friction of Fluids on the Motion of Pendulums. Transactions of the Cambridge Philosophical Society 9, 8-106.

Ghanem, A., Lemenand, T., Della Valle, D., Peerhossaini, H. (2014): Static mixers. Mechanisms, applications, and characterization methods - A review. Chemical Engineering Research and Design 92 (2), 205-228.

Grund, G., Schumpe, A., Deckwer, W.-D. (1992): Gas-Liquid mass transfer in a bubble column with organic liquids. Chemical Engineering Science 47 (13), 3509-3516.

Harmathy, T. Z. (1960): Velocity of large drops and bubbles in media of infinite or restricted extent. AIChE Journal 6 (2), 281-288.

Heyouni, A., Roustan, M., Do-Quang, Z. (2002): Hydrodynamics and mass transfer in gasliquid flow through static mixers. Chemical Engineering Science 57 (16), 3325-3333.

Hobbs, D. M., Muzzio, F. J. (1998): Optimization of a static mixer using dynamical systems techniques. Chemical Engineering Science 53 (18), 3199-3213.

Kazakis, N. A., Mouza, A. A., Paras, S. V. (2008): Experimental study of bubble formation at metal porous spargers: Effect of liquid properties and sparger characteristics on the initial bubble size distribution. Chemical Engineering Journal 137 (2), 265-281.

Keshav, T. R., Somaraju, P., Kalyan, K., Saroha, A. K., Nigam, K.D.P. (2008): Liquid phase residence time distribution for gas-liquid flow in Kenics static mixer. Chemical Engineering and Processing: Process Intensification 47 (12), 2275-2280.

Kováts, P., Thévenin, D., Zähringer, K. (2017): Characterizing fluid dynamics in a bubble column aimed for the determination of reactive mass transfer. Heat and Mass Transfer 54, $453-461$.

Lage, P.L.C., Espósito, R. O. (1999): Experimental determination of bubble size distributions in bubble columns: prediction of mean bubble diameter and gas hold up. Powder Technology 101, 142-150.

Laupsien, D., Cockx, A., Line, A. (2017): Bubble Plume Oscillations in Viscous Fluids. Chemical Engineering \& Technology 40, 1484-1493 
Lemenand, T., Della Valle, D., Zellouf, Y., Peerhossaini, H. (2003): Droplets formation in turbulent mixing of two immiscible fluids in a new type of static mixer. International Journal of Multiphase Flow 29 (5), 813-840.

Li, H. Z., Fasol, C., Choplin, L. (1997): Pressure Drop of Newtonian and Non-Newtonian Fluids Across a Sulzer SMX Static Mixer. Chemical Engineering Research and Design 75 (8), 792-796.

Link, J., Zeilstra, C., Deen, N., Kuipers, H. (2008): Validation of a Discrete Particle Model in a 2D Spout-Fluid Bed Using Non-Intrusive Optical Measuring Techniques. Canadian Journal of Chemical Engineering 82, 30-36.

Liu, S., Hrymak, A. N., Wood, P. E. (2006): Design modifications to SMX static mixer for improving mixing. AIChE Journal 52 (1), 150-157.

Liu, Z., Zheng, Y., Jia, L., Zhang, Q. (2005): Study of Bubble Induced Flow Structure using PIV. Chemical Engineering Science 60, 3537-3552.

Lunde, K., Perkins, R. J. (1998): Shape Oscillations of Rising Bubbles. Fascination of Fluid Dynamics: A Symposium in Honour of Leen van Wijngaarden. Springer Netherlands, 387408.

Luo, S. J., Fei, W.Y., Y. Song, X., Li, H. Z.(2008): Effect of Channel Opening Angle on the Performance of Structured Packings. Chemical Engineering Journal 144, 227-234.

Madhuranthakam, C. M. R., Pan, Q., Rempel, G. L. (2009a): Hydrodynamics in Sulzer SMX Static Mixer with Air/Water System. Industrial \& Engineering Chemistry Research 48 (2), 719-726.

Madhuranthakam, C. M. R., Pan, Q., Rempel, G. L. (2009b): Residence time distribution and liquid holdup in Kenics ${ }^{\circledR}$ KMX static mixer with hydrogenated nitrile butadiene rubber solution and hydrogen gas system. Chemical Engineering Science 64 (14), 3320-3328.

Meijer, H., Singh, M., Anderson, P. (2012): On the performance of static mixers: A quantitative comparison. Progress in Polymer Science 37, 1333-1349.

Mendelson, H. D. (1967): The prediction of bubble terminal velocities from wave theory. AIChE Journal 13.

Montante, G., Coroneo, M., Paglianti, A. (2016): Blending of miscible liquids with different densities and viscosities in static mixers. Chemical Engineering Science 141, 250-260.

Mougin, G., Magnaudet, J. (2001): Path Instability of a Rising Bubble. Physical Review Letters 88 (1). 14502.

Paglianti, A., Montante, G. (2013): A mechanistic model for pressure drops in corrugated plates static mixers. Chemical Engineering Science 97, 376-384.

Pahl, M. H., Muschelknautz, E. (1982): Static Mixers and Their Applications. International chemical engineering 22, 197-205.

Park, T., Sung, Y., Kim, T., Lee, I., Choi, G., Kim, D. (2014): Effect of static mixer geometry on flow mixing and pressure drop in marine SCR applications. International Journal of Naval Architecture and Ocean Engineering 6 (1), 27-38.

Paul, E. L., Atiemo-Obeng, V. A., Kresta, S. M. (2004): Handbook of industrial mixing. Science and practice. Hoboken N.J.: Wiley-Interscience.

Raffel, M., Willert, Christian, Kompenhans, Juergen (1998): Particle Image Velocimetry. A Practical Guide. 
Rauline, D, Tanguy P. A., Le Blevec, J-M., Bousquet, J. (1998): Numerical investigation of the performance of several static mixers. The Canadian Journal of Chemical Engineering 76, $527-535$

Rauline, D., Le Blévec, J.-M., Bousquet, J., Tanguy, P. A. (2000): A Comparative Assessment of the Performance of the Kenics and SMX Static Mixers. Chemical Engineering Research and Design 78 (3), 389-396.

Raymond, F., Rosant, J.-M. (2000): A numerical and experimental study of the terminal velocity and shape of bubbles in viscous liquids. Chemical Engineering Science 55 (5), 943955.

Regner, M., Östergren, K., Trägårdh, C. (2006): Effects of geometry and flow rate on secondary flow and the mixing process in static mixers - a numerical study. Chemical Engineering Science 61 (18), 6133-6141.

Saffman, P. G. (1956): On the rise of small air bubbles in water. Journal of Fluid Mechanics 1 (3), 249-275.

Sánchez Pérez, J. A., Rodríguez Porcel, E. M., Casas López, J. L., Fernández Sevilla, J. M., Chisti, Y. (2006): Shear rate in stirred tank and bubble column bioreactors. Chemical Engineering Journal 124 (1-3), 1-5.

Sathe, M., Joshi, J., Evans, G. (2013): Characterization of turbulence in rectangular bubble column. Chemical Engineering Science 100, 52-68.

Sathe, M. J., Thaker, I. H., Strand, T. E., Joshi, J. B. (2010): Advanced PIV/LIF and shadowgraphy system to visualize flow structure in two-phase bubbly flows. Chemical Engineering Science 65 (8), 2431-2442.

Settles, G. S. (2001): Schlieren and Shadowgraph Techniques: Visualizing Phenomena in Transparent Media: Springer-Verlag Berlin and Heidelberg GmbH \& Co. K.

Singh, M. K., Anderson, P. D., Meijer, H. E. H. (2009): Understanding and Optimizing the SMX Static Mixer. Macromolecular Rapid Communications 30 (4-5), 362-376.

Sobieszuk, P., Aubin, J., Pohorecki, R. (2012): Hydrodynamics and Mass Transfer in GasLiquid Flows in Microreactors. Chemical Engineering \& Technology 35 (8), 1346-1358.

Thakur, R. K., Vial, Ch., Nigam, K.D.P., Nauman, E. B., Djelveh, G. (2003): Static Mixers in the Process Industries-A Review. Chemical Engineering Research and Design 81 (7), 787826.

Tizaoui, C., Zhang, Y. (2010): The modelling of ozone mass transfer in static mixers using Back Flow Cell Model. Chemical Engineering Journal 162 (2), 557-564.

Tomiyama, A. (2002): Single bubbles in stagnant liquids and in linear shear flows. Workshop on Measurement Technology (MTWS5), 2002.

Tomiyama, A., Kataoka, I., Zun, I., Sakaguchi, T. (1998): Drag Coefficients of Single Bubbles under Normal and Micro Gravity Conditions. JSME International Journal Series B 41, 472-479.

Tripathi, M. K., Sahu, K. C., Govindarajan, R. (2015): Dynamics of an initially spherical bubble rising in quiescent liquid. Nature Communications 6, 6268.

Ugwu, C. U., Ogbonna, J. C., Tanaka, H. (2002): Improvement of mass transfer characteristics and productivities of inclined tubular photobioreactors by installation of internal static mixers. Applied Microbiology and Biotechnology 58 (5), 600-607. 
Voulgaropoulos, V., Angeli, P. (2017): Optical measurements in evolving dispersed pipe flows. Exp. Fluids 58 (12), 170.

Wallis, G. B. (1974): The terminal speed of single drops or bubbles in an infinite medium. International Journal of Multiphase Flow 1 (4), 491-511.

Wild, G., Poncin, S., Li, H. Z., Olmos, E. (2003): Some Aspects of the Hydrodynamics of Bubble Columns. International Journal of Chemical Reactor Engineering 1, 1-36.

Willems, P., Deen, N. G., Kemperman, A.J.B., Lammertink, R.G.H., Wessling, M., van Sint Annaland, M. et al. (2010): Use of Particle Imaging Velocimetry to measure liquid velocity profiles in liquid and liquid/gas flows through spacer filled channels. Journal of Membrane Science 362 (1), 143-153.

Zaruba, A., Krepper, E., Prasser, H. M., Reddy Vanga, B. N. (2005): Experimental study on bubble motion in a rectangular bubble column using high-speed video observations. Flow Measurement and Instrumentation 16 (5), 277-287. 